\title{
Determinants of Infant Mortality in Samdrup Jongkhar District, Bhutan
}

\author{
Hari Prasad Pokhrel ${ }^{1}$, Dawa Gyeltshen ${ }^{2}$, Tsheten ${ }^{3}$, Tulsi Ram Sharma ${ }^{4}$, Pema Tshewang ${ }^{5}$, \\ Kezang Dorji ${ }^{6}$, Dema Yangzom ${ }^{7}$
}

${ }^{1}$ Gidakom Hospital, Ministry of Health, Bhutan, ${ }^{2}$ Dzongkhar Health Sector, Dzongkhag Administration, Samdrup Jongkhar, Bhutan, ${ }^{3}$ Royal Centre for Disease Control, Ministry of Health, Bhutan, ${ }^{4}$ Eastern Regional Referral Hospital, Mongar, Bhutan, ${ }^{5}$ Dzongkhar Health Sector, Dzongkhag Administration, Samdrup Jongkhar, Bhutan, ${ }^{6}$ Samdrup Jongkhar General Hospital, Samdrup Jongkhar, Bhutan, ${ }^{7}$ Samdrup Jongkhar General Hospital, Samdrup Jongkhar, Bhutan

*Corresponding author: Hari Prasad Pokhrel, hari88pokhrel@gmail.com

Received 05 February 2019;

Accepted 21 February 2019;

Published 24 February 2019

\begin{abstract}
Samdrup Jongkhar district has reported an increasing trend in infant mortality rates over the recent years. This study aimed to identify its determinants. A population based case-control study was conducted in May 2018. Case group comprised of 79 infants who died between $1^{\text {st }}$ January $2015-30^{\text {th }}$ April 2018 while 158 living children born during the same period and residing closest to the home where infant mortality occurred were recruited as controls. Premature new-borns and those with low birth weight were 5.9 times and 4.1 times more likely to die respectively. New-borns whose mother received better ante-natal and post-natal care were more likely to survive. Over 50\% of the deaths occurred at home and around two-thirds of deaths occurred during the post-natal period. Implementing a multi-stakeholder collaborative approach including local leaders, village health workers and religious leaders would be useful in reassuring parents to seek early medical care during childhood illness.
\end{abstract}

Keywords: Determinants, Infant mortality, Samdrup Jongkhar, Bhutan

\section{Background}

Infant mortality is an important indicator of health and well-being of the population. ${ }^{[1]}$ Globally 4.5 million infant deaths were reported in 2015 and it accounts for $75 \%$ of all under-five deaths. Close to 1 million children died on the first day of their life in 2016. Majority of these deaths occur in developing countries where accessibility to healthcare is low. ${ }^{[2]}$ Over the past one and a half decade, Bhutan has made substantial progress in reduction of under-five deaths which reduced from 84.0 per 1000 live births in 2000 to 37.3 in 2016. Significant proportion of these under-five deaths are contributed by infant deaths as infant mortality rate was 30.0 per 1000 live births in $2016,{ }^{[3]}$ and similar trends have been reported globally. ${ }^{[4]}$ Samdrup Jongkhar district has reported an increasing trend in infant and under-five mortality rates over the recent years. ${ }^{[5]}$ Similar findings were reported by the Population and Housing Census of Bhutan 2017. ${ }^{[6]}$ Preventing newborn deaths contributes to healthier and more prosperous societies. ${ }^{[7]}$ The United Nations Sustainable Development Goal calls upon member states to end all preventable deaths of newborns and children under-five with all countries aiming to reduce neo-natal mortality to 12 per 1000 live births and under-five mortality to 25 per 1000 live births by $2030 .^{[8]}$ Reliable information on the magnitude, trends and causes of death of children helps decision-makers to assess programmatic needs, prioritize interventions and monitor progress. It is crucial for planning and evaluating effectiveness of health services and interventions. ${ }^{[9]}$ However, no studies have been conducted at the moment to address this situation. This study aimed to identify the determinants of infant mortality in Samdrup Jongkhar.

\section{Methodology}

A population based case-control study matched for place, month and year of birth was conducted in May 2018. Records of infant deaths were obtained from data maintained at the district health office. Infants who died in the district but whose parents were not recorded as resident of the district in any of the annual household surveys between 2014-2017 were excluded from the study. Case group comprised of 79 infants ( $96.3 \%$ of the case population) who died between 1st January 2015-30 ${ }^{\text {th }}$ April 2018 while 158 living children born during the same period and living closest to the home where infant mortality occurred were recruited as controls. Data collection was done by trained health assistants using a validated and pre-tested structured questionnaire. Socio-demographic data were collected from the mothers by personal interview at their 
homes while health services related data were extracted from the maternal and child (MCH) hand books and $\mathrm{MCH}$ registers maintained at various health facilities in the district. Data entry was done using Epi Data version 3.1 and analyzed using SPSS version 22. Descriptive were presented as frequencies, means and percentages. Chi-Square test was done to assess the associations between independent and dependent variables keeping p-value of $<0.05$ as statistically significant. Univariate analysis was done to estimate crude odds ratio (OR) and $95 \%$ confidence interval (95\% CI) for all the significant variables. Ethical approval was granted by the Research Ethics Board of Health, Ministry of Health, Bhutan (Ref. No. REBH/Approval/2017/082). Participation in this study was voluntary and data was collected only after obtaining written consent.

Table 1: Maternal and infant history $(n=237)$

\begin{tabular}{|c|c|c|c|c|c|}
\hline \multirow[t]{2}{*}{ Variables } & \multirow[t]{2}{*}{ Total } & \multicolumn{2}{|c|}{ Case (79) } & \multicolumn{2}{|c|}{ Control (158) } \\
\hline & & $\mathrm{n}$ & $\%$ & $\mathrm{n}$ & $\%$ \\
\hline \multicolumn{6}{|l|}{ Maternal age at birth of the child } \\
\hline$\leq 30$ & 161 & 46 & 58.2 & 115 & 72.8 \\
\hline$\geq 31$ & 76 & 33 & 41.8 & 43 & 27.2 \\
\hline Mean, SD & & \multicolumn{2}{|c|}{$28.4,6.4$} & \multicolumn{2}{|c|}{$26.8,5.6$} \\
\hline \multicolumn{6}{|l|}{ Maternal education } \\
\hline No education & 68 & 33 & 41.8 & 35 & 22.2 \\
\hline Educated & 169 & 46 & 58.2 & 123 & 77.8 \\
\hline \multicolumn{6}{|l|}{ Maternal occupation } \\
\hline HW/Farmer & 187 & 66 & 83.5 & 121 & 76.6 \\
\hline Private & 26 & 9 & 11.4 & 17 & 10.8 \\
\hline Government & 24 & 4 & 5.1 & 20 & 12.7 \\
\hline \multicolumn{6}{|l|}{ Type of family } \\
\hline Nuclear & 169 & 56 & 70.9 & 113 & 71.5 \\
\hline Extended & 68 & 23 & 29.1 & 45 & 28.5 \\
\hline \multicolumn{6}{|l|}{ Monthly family income } \\
\hline less than 5000 & 64 & 26 & 32.9 & 38 & 24.1 \\
\hline $5001-10000$ & 68 & 23 & 29.1 & 45 & 28.5 \\
\hline $100001-20000$ & 65 & 19 & 24.1 & 46 & 29.1 \\
\hline 20001 and above & 40 & 11 & 13.9 & 29 & 18.4 \\
\hline \multicolumn{6}{|l|}{ History of chronic Disease } \\
\hline Yes & 21 & 8 & 10.1 & 13 & 8.2 \\
\hline No & 216 & 71 & 89.9 & 145 & 91.8 \\
\hline \multicolumn{6}{|l|}{ Complications during pregnancy } \\
\hline Yes & 18 & 10 & 12.7 & 8 & 5.1 \\
\hline No & 219 & 69 & 87.3 & 150 & 94.9 \\
\hline \multicolumn{6}{|c|}{ Trimester of ANC booking $(n=236)$} \\
\hline 1st Trimester & 108 & 36 & 45.6 & 72 & 45.9 \\
\hline 2nd Trimester & 115 & 38 & 48.1 & 77 & 49 \\
\hline $3^{\text {rd }}$ & 13 & 5 & 6.3 & 8 & 5.1 \\
\hline \multicolumn{6}{|l|}{ Number of ANC visits } \\
\hline $1-3$ & 19 & 9 & 11.4 & 10 & 6.3 \\
\hline $4-7$ & 129 & 46 & 58.2 & 83 & 52.5 \\
\hline 8 and above & 89 & 24 & 30.4 & 65 & 41.1 \\
\hline \multicolumn{6}{|l|}{ Gestational Age } \\
\hline$<37$ weeks & 24 & 17 & 21.5 & 7 & 4.4 \\
\hline $37-42$ weeks & 213 & 62 & 78.5 & 151 & 95.6 \\
\hline \multicolumn{6}{|l|}{ Intrapartum complications } \\
\hline Yes & 30 & 8 & 10.1 & 22 & 13.9 \\
\hline No & 207 & 71 & 89.9 & 136 & 86.1 \\
\hline \multicolumn{6}{|l|}{ Place of birth } \\
\hline District Hospital & 107 & 33 & 41.8 & 74 & 46.8 \\
\hline Basic Health Unit & 62 & 19 & 24.1 & 43 & 27.2 \\
\hline Tertiary Hospitals & 33 & 6 & 7.6 & 27 & 17.1 \\
\hline Home & 31 & 17 & 21.5 & 14 & 8.9 \\
\hline Ambulance/ En-route to HF & 4 & 4 & 5.0 & 0 & 0.0 \\
\hline \multicolumn{6}{|l|}{ Type of delivery } \\
\hline Normal & 198 & 67 & 84.8 & 131 & 82.9 \\
\hline Caesarean & 39 & 12 & 15.2 & 27 & 17.1 \\
\hline \multicolumn{6}{|l|}{ Gender } \\
\hline Female & 120 & 37 & 46.8 & 83 & 52.5 \\
\hline
\end{tabular}

$\underline{\text { www.ijirms.in }}$
Over three-fourths (77.8\%) of the mothers in the control group had education compared to $58.2 \%$ in the case group. Less than onethirds $(30.4 \%)$ of the mothers in case group availed over eight antenatal care (ANC) services compared to $41.1 \%$ in the control group. One-fifths $(21.4 \%)$ of the infants in the case group were born before 37 weeks of gestation and around a quarter (25.3\%) of them were underweight. Over one-fifth $(21.5 \%)$ of the infants in the case group were born at home. Mothers availing subsequent post-natal care (PNC) services declined gradually in both the groups with over half $(57.0 \%)$ of the mothers in the case group not availing the fourth post-natal care (table 1). 


\begin{tabular}{|c|c|c|c|c|c|}
\hline Male & 117 & 42 & 53.2 & 75 & 47.5 \\
\hline \multicolumn{6}{|c|}{ Birth Weight (grams) } \\
\hline$<2500$ & 32 & 20 & 25.3 & 12 & 7.6 \\
\hline $2500-4499$ & 205 & 59 & 74.7 & 146 & 92.4 \\
\hline \multicolumn{6}{|l|}{ Birth Order } \\
\hline 1 and 2 & 132 & 35 & 44.3 & 97 & 61.4 \\
\hline$\leq 3$ & 105 & 44 & 55.7 & 61 & 38.6 \\
\hline \multicolumn{6}{|c|}{ New born complications } \\
\hline Yes & 54 & 22 & 27.8 & 32 & 20.3 \\
\hline No & 183 & 57 & 72.2 & 126 & 79.7 \\
\hline \multicolumn{6}{|c|}{ History of Post Natal Care (PNC) } \\
\hline \multicolumn{6}{|l|}{ PNC 1} \\
\hline Yes & 188 & 51 & 64.6 & 137 & 86.7 \\
\hline No & 49 & 28 & 35.4 & 21 & 13.3 \\
\hline \multicolumn{6}{|l|}{ PNC 2 } \\
\hline Yes & 185 & 49 & 62 & 136 & 86.1 \\
\hline No & 52 & 30 & 38 & 22 & 13.9 \\
\hline \multicolumn{6}{|l|}{ PNC 3} \\
\hline Yes & 167 & 41 & 51.9 & 126 & 79.7 \\
\hline No & 70 & 38 & 48.1 & 32 & 20.3 \\
\hline \multicolumn{6}{|l|}{ PNC 4} \\
\hline \begin{tabular}{l|l} 
& Yes \\
\end{tabular} & 135 & 34 & 43.0 & 101 & 63.9 \\
\hline No & 102 & 45 & 57.0 & 57 & 36.1 \\
\hline
\end{tabular}

Around two-thirds (65.8\%) of the deaths occurred during the post-neonatal period. Over half of the deaths occurred at home (26.6\%) and district hospital (25.3\%). The cause of death was not known for $43.0 \%$ of the infants (Table 2).

Table 2: Descriptive of cases $(n=79)$

\begin{tabular}{|c|c|c|}
\hline Variables & $\mathbf{n}$ & $\%$ \\
\hline \multicolumn{3}{|l|}{ Gender } \\
\hline Male & 42 & 53.2 \\
\hline Female & 37 & 46.8 \\
\hline \multicolumn{3}{|l|}{ Age at death } \\
\hline within 24 hours & 15 & 19.0 \\
\hline 1-7 days & 7 & 8.9 \\
\hline 8-28 days & 5 & 6.3 \\
\hline more than 28 days & 52 & 65.8 \\
\hline \multicolumn{3}{|l|}{ Place of death } \\
\hline Home & 21 & 26.6 \\
\hline District Hospital & 20 & 25.3 \\
\hline Ambulance & 18 & 22.8 \\
\hline Tertiary Hospitals & 15 & 19.0 \\
\hline Basic Health Units & 5 & 6.3 \\
\hline \multicolumn{3}{|l|}{ Cause of death } \\
\hline Unknown & 34 & 43.0 \\
\hline Pneumonia & 8 & 10.1 \\
\hline Preterm & 8 & 10.1 \\
\hline Sudden death & 5 & 6.3 \\
\hline Unknown fever & 4 & 5.1 \\
\hline Aspiration & 4 & 5.1 \\
\hline Meningitis & 3 & 3.8 \\
\hline Others & 13 & 16.5 \\
\hline
\end{tabular}

Over one-fourths (30.8\%) of the post-neonatal deaths occurred at home followed by $26.9 \%$ in ambulance. $40 \%$ of the deaths occurring during the first 24 hours of life occurred at the district hospital (table 3).

Table 3: Age at death by place of death $(n=79)$

\begin{tabular}{|l|c|c|c|c|c|c|c|c|c|c|}
\hline Place of Death & \multicolumn{2}{|c|}{ Total } & \multicolumn{2}{c|}{ Within 24 hours } & \multicolumn{2}{c|}{$\mathbf{1 - 7}$ days } & \multicolumn{2}{c|}{ 8-28 days } & \multicolumn{2}{c|}{ Post-Neonatal } \\
\hline & $\mathbf{N}$ & $\mathbf{\%}$ & $\mathbf{n}$ & $\mathbf{\%}$ & $\mathbf{N}$ & $\mathbf{\%}$ & $\mathbf{n}$ & $\mathbf{\%}$ & $\mathbf{n}$ & $\mathbf{\%}$ \\
\hline Home & 21 & 26.6 & 3 & 20 & 1 & 14.3 & 1 & 20 & 16 & 30.8 \\
\hline District Hospital & 20 & 25.3 & 6 & 40 & 2 & 28.6 & 2 & 40 & 10 & 19.2 \\
\hline Ambulance & 18 & 22.8 & 2 & 13.3 & 2 & 28.6 & 0 & 0 & 14 & 26.9 \\
\hline Tertiary Hospitals & 15 & 19 & 3 & 20 & 2 & 28.6 & 1 & 20 & 9 & 17.3 \\
\hline BHU & 5 & 6.3 & 1 & 6.7 & 0 & 0 & 1 & 20 & 3 & 5.8 \\
\hline Total & $\mathbf{7 9}$ & $\mathbf{1 0 0}$ & $\mathbf{1 5}$ & $\mathbf{1 0 0}$ & $\mathbf{7}$ & $\mathbf{1 0 0}$ & $\mathbf{5}$ & $\mathbf{1 0 0}$ & $\mathbf{5 2}$ & $\mathbf{1 0 0}$ \\
\hline
\end{tabular}


BHU: Basic Health Unit

Crude estimates show that infants born before 37 weeks were 5.9 times more likely to die compared to those infants born after 37 weeks. Infants with a birth weight less than 2500 grams were 4.1 times more likely to die. Infants who were not born in health facilities were 3.7 times more likely to die (Table 4).

Table 4: Association between the independent and dependent variable $(n=237)$

\begin{tabular}{|c|c|c|c|c|c|c|c|c|c|c|}
\hline \multirow[t]{2}{*}{ Variables } & & \multirow[t]{2}{*}{ Total } & \multicolumn{2}{|c|}{ Case (79) } & \multicolumn{2}{|c|}{ Control (158) } & \multicolumn{4}{|c|}{ Crude Estimates } \\
\hline & & & $\mathrm{n}$ & $\%$ & $\mathrm{n}$ & $\%$ & p-value & OR & & \\
\hline \multicolumn{11}{|c|}{ Maternal age at birth } \\
\hline & $\leq 30$ & 161 & 46 & 58.2 & 115 & 72.8 & \multirow[t]{2}{*}{0.025} & 1 & & \\
\hline & $\geq 31$ & 76 & 33 & 41.8 & 43 & 27.2 & & 1.9 & 1.1 & 3.4 \\
\hline \multicolumn{11}{|c|}{ Education of the mother } \\
\hline & Educated & 169 & 46 & 58.2 & 123 & 77.8 & \multirow[t]{2}{*}{0.002} & 1 & & \\
\hline & No education & 68 & 33 & 41.8 & 35 & 22.2 & & 2.5 & 1.4 & 4.5 \\
\hline \multicolumn{11}{|c|}{ Number of ANC visits } \\
\hline & $\geq 7$ & 123 & 33 & 41.8 & 90 & 57 & \multirow[t]{2}{*}{0.028} & 1 & & \\
\hline & $\leq 6$ & 114 & 46 & 58.2 & 68 & 43 & & 1.8 & 1.1 & 3.2 \\
\hline \multicolumn{11}{|c|}{ Complications during pregnancy } \\
\hline & No & 219 & 69 & 87.3 & 150 & 94.9 & \multirow[t]{2}{*}{0.044} & 1 & & \\
\hline & Yes & 18 & 10 & 12.7 & 8 & 5.1 & & 2.7 & 1 & 7.2 \\
\hline \multicolumn{11}{|c|}{ Gestational Age } \\
\hline & $37-42$ & 216 & 64 & 81 & 152 & 96.2 & \multirow[t]{2}{*}{0.000} & 1 & & \\
\hline & $<37$ weeks & 21 & 15 & 19 & 6 & 3.8 & & 5.9 & 2.2 & 16 \\
\hline \multicolumn{11}{|c|}{ Place of delivery } \\
\hline & Health facility & 202 & 58 & 73.4 & 144 & 91.1 & \multirow[t]{2}{*}{0.001} & 1 & & \\
\hline & Outside health facility & 35 & 21 & 26.6 & 14 & 8.9 & & 3.7 & 1.8 & 7.8 \\
\hline \multicolumn{11}{|c|}{ Birth weight } \\
\hline & Normal & 205 & 59 & 74.7 & 146 & 92.4 & \multirow[t]{2}{*}{0.000} & 1 & & \\
\hline & Low birth weight & 32 & 20 & 25.3 & 12 & 7.6 & & 4.1 & 1.9 & 9 \\
\hline \multicolumn{11}{|c|}{ Birth order } \\
\hline & $\leq 2$ & 132 & 35 & 44.3 & 97 & 61.4 & \multirow[t]{2}{*}{0.013} & 1 & & \\
\hline & $\leq 3$ & 105 & 44 & 55.7 & 61 & 38.6 & & 2 & 1.2 & 3.5 \\
\hline \multicolumn{11}{|c|}{ History of availing post-natal care services } \\
\hline \multicolumn{11}{|l|}{ PNC 1 } \\
\hline & Yes & 188 & 51 & 64.6 & 137 & 86.7 & \multirow[t]{2}{*}{0.000} & 1 & & \\
\hline & No & 49 & 28 & 35.4 & 21 & 13.3 & & 3.6 & 1.9 & 6.9 \\
\hline PNC 2 & & & & & & & & & & \\
\hline & Yes & 185 & 49 & 62 & 136 & 86.1 & 0.000 & 1 & & \\
\hline & No & 52 & 30 & 38 & 22 & 13.9 & & 3.8 & 2 & 7.2 \\
\hline PNC 3 & & & & & & & & & & \\
\hline & Yes & 167 & 41 & 51.9 & 126 & 79.7 & 0.000 & 1 & & \\
\hline & No & 70 & 38 & 48.1 & 32 & 20.3 & & 3.6 & 2 & 6.6 \\
\hline PNC 4 & & & & & & & & & & \\
\hline & Yes & 135 & 34 & 43 & 101 & 63.9 & 0.002 & 1 & & \\
\hline & No & 102 & 45 & 57 & 57 & 36.1 & & 2.3 & 1.4 & 4.1 \\
\hline
\end{tabular}

Only significant variables at p-value 0.05 presented

\section{Discussion}

Preterm births and low birth weight had the highest influence on survival of an infant. Children born before 37 weeks of pregnancy are defined as preterm children. ${ }^{[10]}$ The study found that infants born before 37 weeks of gestation were 5.9 times more likely to die compared to those born after 37 weeks of gestation. The World Health Organization reports that around one million children die due to complications arising from preterm birth. ${ }^{[11]}$ Common causes of preterm births include multiple pregnancies, infections and chronic diseases like hypertension and diabetes. ${ }^{[10]}$ Birth weight of less than 2500 grams is classified as low birth weight. ${ }^{[12]}$ The data suggest that infants with low birth weight were 4.1 times more likely to die compared to infants with normal birth weight. A cohort study conducted in Ghana reported that low birth weight children had higher rates of illnesses and had higher mortality rates compared to other children. The risk of death increased with the increase in severity of underweight. ${ }^{[13]}$ The World Health Organization points out that the main causes of newborn deaths are prematurity, low birth-weight, infections, birth asphyxia and birth trauma which accounts for around $80 \%$ of the total newborn deaths. ${ }^{[14]}$

Infants born to mothers who had complications during pregnancy were 2.7 times more likely to die. Quality ante-natal care is important in identifying and managing complications during 
pregnancy. A cohort study conducted in India reported that complications during pregnancy leads to still births, low birth weight and neonatal deaths. ${ }^{[15]}$ The study found that availing antenatal, intra-natal and post-natal care services were positively associated with infant survival. Infants whose mother availed 6 or more number of ante-natal care services were 1.8 times more likely to survive and infants born in health facilities were 3.7 times more likely to survive. A study conducted in Iran reported that home delivery and less than four ante-natal visits significantly increased the chance of death. ${ }^{[16]}$ Quality ante-natal care, care at the time of birth and post-natal care for newborns and their mothers are vital to combating newborn deaths. ${ }^{[17]}$

Children born to women who were over 31 years of age during birth were 1.8 times more likely to die. Mothers giving birth at an advanced age can lead to reduced quality of care due to poor birth spacing. This is intricately connected with higher birth order infants being less likely to survive as reported in this study. The WHO recommends at-least 24 months' interval after a live birth. ${ }^{[18]}$ Infants whose mothers had no education were 2.5 times more likely to die compared to those born to an educated mother. Maternal education can affect the quality care and feeding practices which is crucial for the survival of an infant during the early days of life. Literature show that many infants do not receive optimal feeding. ${ }^{[19]}$ Pre-lacteal feeding and sub-optimal infant and young child feeding practices (IYCF) were reported by the national nutrition survey of Bhutan $2015^{[20]}$ which was confirmed during the in-depth analysis. ${ }^{[21]}$ Inadequate knowledge on breastfeeding ${ }^{[22]}$ and mothers expelling out colostrum 23 have been reported by earlier studies conducted in other parts of Bhutan.

The study found that over 50\% deaths occurred at home (26.6\%) and district hospital (25.3\%). Educating parents on the need to seek medical care even during mild illnesses could help reduce preventable deaths. Shortage of skilled medical professionals such as pediatrician and pediatric nurses in the district can partly explain the high proportion of deaths at the district hospital. Studies have shown that access to medicines and skilled health professionals can help reduce preventable deaths. ${ }^{[4]}$ A child's risk of dying is highest in the first 28 days of life which is called as the neonatal period. ${ }^{[17]}$ The national annual health bulletin reports that around $56 \%$ of the under-five deaths are newborn deaths. ${ }^{[3]}$ However, this study found that around two-thirds of the deaths occurred during the postneonatal period. Over half of these post-neonatal deaths occurred either at home or in ambulance during transit the health facilities. Although literature suggest that undernutrition, non-breastfed children, low-birth weight, poor hygiene practices, unsafe drinking water and food as major risk factors of death in post-neonatal children $^{[17]}$ this trend also suggests of delayed health seeking behavior in the community. Religious rituals and local healers are first preference of rural population in Bhutan over health services. A prospective study conducted in Bangladesh reported of delayed health seeking behavior among parents who lost their children. ${ }^{[24]}$ Poor health care seeking for febrile conditions in children underfive was found among many African countries. ${ }^{[25]}$ The cause of death could not be ascertained for $43 \%$ of the cases. Ascertaining the cause of death is crucial for planning and targeted interventions. ${ }^{[9]}$ Small sample size was a major limitation in this study ( $\mathrm{n}$ case $=79$ ). Because of the sparseness of the samples in some strata multivariate regression could not be done. Recall bias can also be a major shortcoming in a case-control study. However, this was addressed by retrieving all the health services related information from the maternal and child handbooks and records maintained at various health facilities across the district.

\section{Conclusion}

The study found that prematurity and low birth weight had the highest influence on survival of an infant. The study observed higher rates of survival in infants who received better ante-natal, intra-natal and post-natal care services. Almost two-thirds of the deaths occurred during the post-natal period. The study recommends to strengthen ante-natal and post-natal care services at all health facilities across the district. Implementing a multistakeholder collaborative approach including local leaders, village health workers and religious leaders would be useful in reassuring parents to seek early medical care during childhood illness. Further study is required to understand the causes of highest proportion of deaths during the post neonatal period.

\section{Acknowledgements}

The authors would like to sincerely thank the Ministry of Health Bhutan, and District Administration Samdrup Jongkhar for permitting us to conduct this study.

\section{Funding}

The study was funded by Dzongkhag (District) Administration, Samdrup Jongkhar, Royal Government of Bhutan

\section{Conflict of interest}

The authors have no conflict of interest.

\section{References}

[1] Reidpath DD, Allotey P. Infant mortality rate as an indicator of population health. J Epidemiol Community Health. 2003; 57:344-6.

[2] World Health Organization. Newborns: Reducing mortality 2016 [cited 2017 18/08]. Available from: http://www.who.int/mediacentre/factsheets/fs333/en/.

[3] Ministry of Health, Thimphu Bhutan. Annual Health Bulletin. 2017.

[4] World Health Organization. Headlines 2018 [cited 2018 17/07]. Available from: http://www.who.int/newsroom/headlines/19-10-2017-7-000-newborns-die-everyday-despite-steady-decrease-in-under-five-mortalitynew-report-says.

[5] District Health Office, Dzongkhag Administration, Samdrup Jongkhar. Vital Statistics. 2017.

[6] National Statistics Bureau, Thimphu Bhutan. Population and Housing Census of Bhutan. 2017.

[7] World Health Organization. Commitment and action for every newborn 2017 [cited 2017 08/18]. Available from: http://www.who.int/mediacentre/commentaries/commitm ent-every-newborn/en/.

[8] United Nations. Sustainable Development Goals 2015 [cited 2017 17/08]. Available from: http://www.un.org/sustainabledevelopment/health/.

[9] Boschi-Pinto C. Estimating child mortality due to diarrhoea in developing countries. Bulletin of the World Health Organization. 2008;86 (9):710-7. 
[10] World Health Organization. Preterm birthd 2017 [cited 2017 23/12]. Available from: http://www.who.int/mediacentre/factsheets/fs363/en/.

[11] World Health Organization. Preterm birth 2018 [cited 2018 13/07]. Available from: http://www.who.int/newsroom/fact-sheets/detail/preterm-birth.

[12] World Health Organization. Global Nutrition Targets 2025: Low birth weight policy brief 2014 [cited 2018 13/07]. Available from: Global Nutrition Targets 2025: Low birth weight policy brief.

[13] O'Leary M, Edmond K, Floyd S, Newton S, Thomas G, Thomas SL. A cohort study of low birth weight and health outcomes in the first year of life, Ghana. Bull World Health Organ. 2017;95(8):574-83.

[14] World Health Organization. Newborns: Reducing Mortality 2017 [cited 2017 23/12]. Available from: http://www.who.int/mediacentre/factsheets/fs333/en/.

[15] Patel A, Prakash AA, Das PK, Gupta S, Pusdekar YV, Hibberd PL. Maternal anemia and underweight as determinants of pregnancy outcomes: cohort study in eastern rural Maharashtra, India. BMJ Open. 2018.

[16] Ansari-Moghaddam A, Sadeghi-Bojd S, Imani M, Movahedinia S, Pourrashidi A, Mohammadi M. A multivariate analysis of factors associated with infant mortality in South-East of Iran. Journal of Pakistan Medical Association. 2014.

[17] World Health Organization. Children: Reducing Mortality 2017 [cited 2017 23/12]. Available from: http://www.who.int/mediacentre/factsheets/fs178/en/.
[18] World Health Organization. Report of a World Health Organization technical consultation on birth spacing. 2005.

[19] World Health Organization. Infant and Young Child Feeding 2018 [Available from: http://www.who.int/news-room/fact-sheets/detail/infantand-young-child-feeding.

[20] Nutrition Program, Ministry of Health, Bhutan. National Nutrition Survey. 2015.

[21] Campbell RK, Aguayo V, Kang Y, Dzed L, Joshi V, Waid $\mathbf{J}$, et al. Infant and young child feeding practices and nutritional status in Bhutan. Matern Child Nutr. 2018;14(3):e12580.

[22] Pokhrel HP, Pavadhgul P, Srisorrachatr S. Factors associated with exclusive breastfeeding practices in western Bhutan. Bhutan Health Journal. 2018;4(1).

[23] Tshering D, Gurung MS, Wangmo N, Pelzom D, Tejativaddhana P, Dzed L. Prevalence of Exclusive Breastfeeding and Factors Associated With Exclusive Breastfeeding of Children in Trongsa District, Bhutan. Asia Pac J Public Health. 2018;30(4):369-77.

[24] Ferdous F, Ahmed S, Das SK, Chisti MJ, Nasrin D, Kotloff KL, et al. Pneumonia mortality and healthcare utilization in young children in rural Bangladesh: a prospective verbal autopsy study. Trop Med Health. 2018; 46:17.

[25] Carvalho LH, Do M, Babalola S, Awantang G, Toso M, Lewicky N, et al. Associations between malaria-related ideational factors and care-seeking behavior for fever among children under five in Mali, Nigeria, and Madagascar. Plos One. 2018;13(1):e0191079. 